\title{
Study Protocol Document Version
}

National Cancer Institute

\section{Source}

National Cancer Institute. Study Protocol Document Version. NCI Thesaurus. Code C93489.

A representation of a particular edition or snapshot of a document containing a study protocol as it exists at a particular point in time. 